\title{
Positioning study of driver's hands in certain areas of the steering wheel
}

\author{
Valentin Amortila*, Elena Mereuta, Silvia Veresiu, Madalina Rus and Costel Humelnicu \\ Dunarea de Jos University of Galati, Faculty of Engineering, Romania
}

\begin{abstract}
The aim of this paper is to analyze driver's hands coordinates on the steering wheel for an optimal and safe driving experience. A good coordination of the driver's action on the controls is the result of a comfortable position that leads to an optimal reaction while driving. The presented study implies using a thermal imaging camera for analysing palms temperature changes in the contact area with the steering wheel. The resulting data shows that the optimal driving position of drivers' hands is $0^{\circ}$ and $180^{\circ}$ associating the steering wheel with and trigonometric circle.
\end{abstract}

\section{Introduction}

Driving in safety conditions implies beside a generally good state of the car, an optimal exploitation, influenced by the driver experience and ability. Even if the ergonomics of the control stations are regulated by rules and standards, and implemented by the automotive manufacturers, the way the commands are used remains a decision only the driver can make. A determinant factor of driver's position and comfort is determined by the position of the steering wheel and the pedals. Studding the biomechanics of the driver position can be challenging. Human body postural analysis can be conducted by using motion capture systems [1-3] or by using MBS models that replicates the behaviour of human body kinematics or dynamics $[4,5]$.

The position of the hands on the steering wheel can vary, depending on the running speed, on the condition and the state of the roads, bringing to the conclusion that drives are more likely to place both hands in the superior half of the steering wheel [6].

Regarding the position of hands on the steering wheel, was proven that female drivers are more likely than man drivers to place both hands on the superior half of the steering wheel, with more $190 \%$ [7].

A study conducted on 230 drivers [8], generated the conclusion that approximatively $25 \%$ of the drivers placed both hands on the superior part of the steering wheel, while over $40 \%$ used only one hand.

Walton D. and Thomas J. A. [7] confirmed that those drivers that had no hands on the superior part of the steering wheel will drive at higher speeds have a riskier way of driving.

It can be observed that there is no unanimous acceptance of hand position. The reason why drivers adopt a certain position is according to the level of comfort.

\footnotetext{
*Corresponding author: valentinamortila@ugal.ro
} 


\section{Materials and methods}

Starting from the controversy generated by the positioning of the hands on the steering wheel, a batch sample of 10 subjects with ages varying from 22.6 to 47.1 years old were analyzed. The subjects were clinically healthy, without motor disabilities and possessing a driving license. The study was conducted on an auto stand that reproduce the commanding post from a vehicle. The experiment consisted in measuring the hands temperature on the steering wheel in three different positions of the quadrant zone (10-2, 9-3 and 7-5) by using a thermal imaging equipment. The used equipment was Optris PI thermal camera that has the following characteristics: optical resolution 160x120 pixels, measurement interval between $-20^{\circ} \mathrm{C} \ldots 900^{\circ} \mathrm{C}$, spectral interval $7.5-13[\mathrm{pm}]$ and precision $\pm 2 \%$.

The subjects were asked to position themselves at the steering wheel and adjust the chair and steering wheel in a way that it is comfortable for them, so that they could easily use the steering wheel and the brakes stand. The measurements were realized in a static regime, without the influence of vibrations or air currents, at a ambient temperature varying between $20-23^{\circ} \mathrm{C}$. The thermal imaging equipment was set to register the minimum temperature from the measurement zone that covered the hands of the subject and a neutral zone, without thermic influence, steering wheel hub (Figure 1). Between the measurements of each of the positions there were brakes of minimum 5 minutes for a thermoregulatory change of the temperature the hands have. The data was collected and analyzed in a spreadsheet programme (Microsoft Excel) in intervals of 10 seconds, for each 5 minute record.

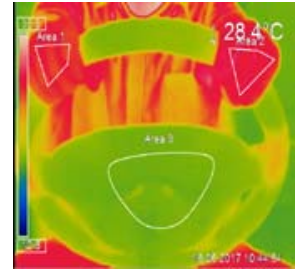

a)

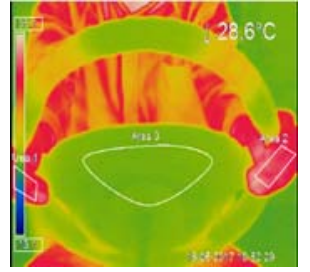

b)

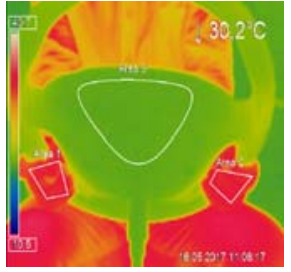

c)

Fig. 1. Hand positions and the thermic measured zones a. first case: zone "10-2", b. second case: zone "9-3", c. third case: zone "7-5".

It was statistically analyzed the parametrical dependent variable "temperature" and the parametrical independent variable "time" through the dependent variable dispersion test, ANOVA, and regression equations of the variable "temperature" for observing if there is any possibility of extrapolation on the whole population.

\section{Results}

The measurements were conducted by using a thermal imaging equipment, Optris PI160, that works in the infrared domain. By studying the indicated zones, it was pointed out the differences of temperature that varied in time due to the hands position on the steering wheel. By analysing the first case, it can be observed a drop of the hands' temperature, for all subjects, with values varying between $0.8^{\circ} \mathrm{C}$ and $2.3^{\circ} \mathrm{C}$. During the second and third cases, the hands' temperature do not act the same for all subjects, in most of the cases it remains the approximately the same as the initial temperature (Figure 2).

The statistical analysis of the correlation between the independent variable, the dependent variable, and of the average as well, lead to different results, depending on the hands positioning. 


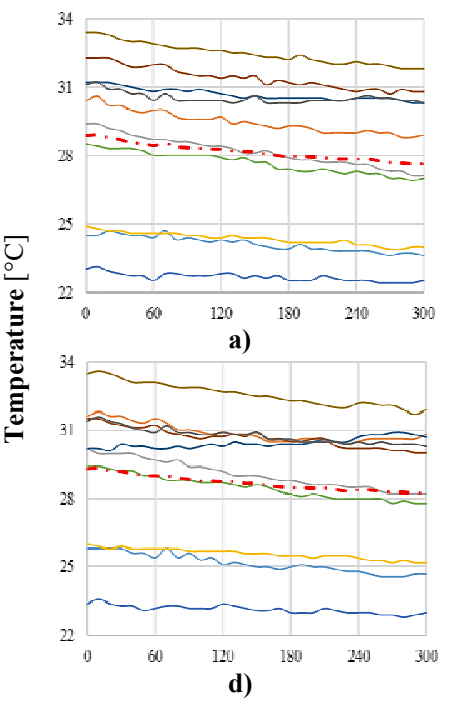

\begin{tabular}{l} 
DRIVER \\
DRIVER \\
\hline DRIVER
\end{tabular}

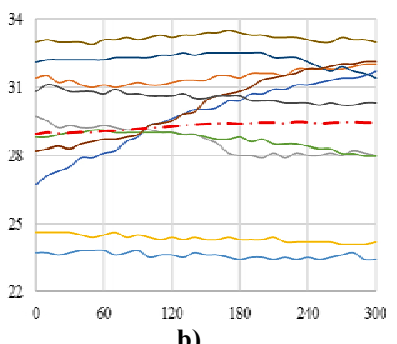

b)

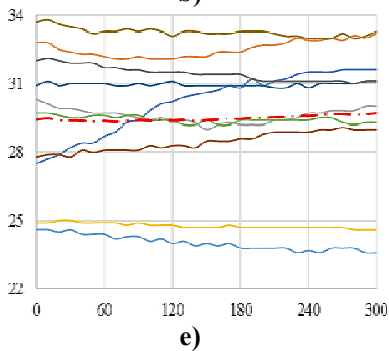

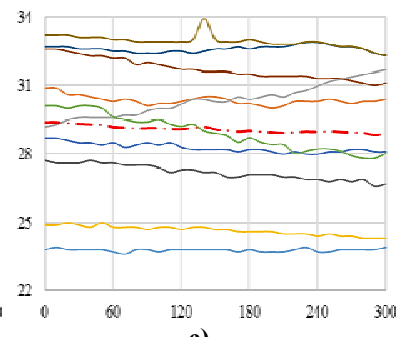

c)

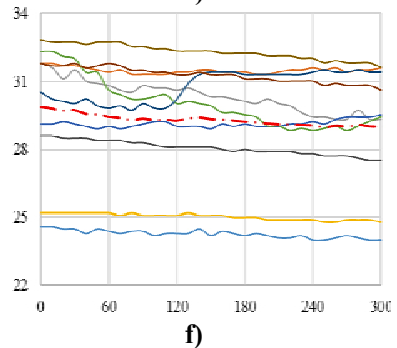

Time [s]

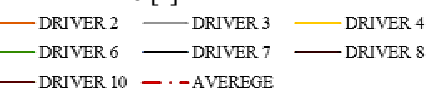

Fig. 2. Variations of the hands' temperature and of the average in the analyzed zones a. right hand for zone "10-2", b. right hand for zone "9-3", c. right hand for zone "7-5", d. left hand for zone "10-2", e. left hand for zone "9-3", f. left hand for zone "7-5".

\subsection{First studied case results}

Through the statistical analysis ANOVA of the hands' temperature in the position "10-2", a value corresponding to the coefficient $p$ was equal to $1.3 \cdot 10^{-284}$ for the right hand and $2 \cdot 10^{-}$ ${ }^{271}$ for the left hand. The resulting values reject the hypothesis that subjects could have the same average temperature of the hands on the followed interval. Thus, it can be observed that the resulted data are statistically meaningful.

It can be observed that there was a strong correlation between the analyzed parameters (time, temperature, average), the Pearson correlation coefficient, $r$, in this case the $r$ coefficient being available in the $[-1 ;-0.8] \mathrm{U}[0.8 ; 1]$ interval.

The strong correlation between the measured temperatures in the "10-2" position is proven by the regression analysis, resulting in a downward linear tendency $(y=a+b x)$, with the equation curve corresponding to the negative regression, for both left hand and right hand (Tables 1 and 2).

Table 1. Regression analysis estimated values for the right hand in the "10-2" position.

\begin{tabular}{|c|c|c|c|c|c|c|c|c|c|c|c|}
\hline & $\begin{array}{c}\text { SUB } \\
1\end{array}$ & $\underset{2}{\text { SUB }}$ & $\begin{array}{c}\text { SUB } \\
3\end{array}$ & $\begin{array}{c}\text { SUB } \\
4\end{array}$ & $\begin{array}{c}\text { SUB } \\
5\end{array}$ & $\begin{array}{c}\text { SUB } \\
6\end{array}$ & $\begin{array}{c}\text { SUB } \\
7\end{array}$ & $\begin{array}{c}\text { SUB } \\
8\end{array}$ & $\begin{array}{c}\text { SUB } \\
9\end{array}$ & $\begin{array}{c}\text { SUB } \\
10\end{array}$ & AVERAGE \\
\hline Intercept & 24,658 & 30,259 & 29,256 & 24,791 & 22,890 & 28,448 & 31,092 & 32,201 & 30,754 & 33,244 & 28,759 \\
\hline Curve & $-0,003$ & $-0,005$ & $-0,007$ & $-0,002$ & $-0,001$ & $-0,005$ & $-0,002$ & $-0,005$ & $-0,001$ & $-0,005$ & $-0,004$ \\
\hline ANGLE $^{\circ}$ & $-0,203$ & $-0,291$ & $-0,392$ & $-0,162$ & $-0,093$ & $-0,287$ & $-0,158$ & $-0,294$ & $-0,092$ & $-0,288$ & $-0,228$ \\
\hline
\end{tabular}

Table 2. Regression analysis estimated values for the left hand in the "10-2" position.

\begin{tabular}{|c|c|c|c|c|c|c|c|c|c|c|c|}
\hline & $\underset{1}{\text { SUB }}$ & $\underset{2}{\text { SUB }}$ & $\underset{3}{\text { SUB }}$ & $\begin{array}{c}\text { SUB } \\
4\end{array}$ & $\begin{array}{c}\text { SUB } \\
5\end{array}$ & $\begin{array}{c}\text { SUB } \\
6\end{array}$ & $\begin{array}{c}\text { SUB } \\
7\end{array}$ & $\begin{array}{c}\text { SUB } \\
8\end{array}$ & $\begin{array}{c}\text { SUB } \\
9\end{array}$ & $\begin{array}{c}\text { SUB } \\
10\end{array}$ & AVERAGE \\
\hline Intercept & 25,806 & 31,468 & 30,102 & 25,948 & 23,406 & 29,324 & 30,118 & 31,334 & 31,306 & 33,433 & 29,224 \\
\hline Curve & $-0,0042$ & $-0,0038$ & $-0,006$ & $-0,002$ & $-0,001$ & $-0,005$ & 0,002 & $-0,004$ & $-0,003$ & $-0,005$ & $-0,0036$ \\
\hline ANGLE $^{\circ}$ & $-0,240$ & $-0,219$ & $-0,378$ & $-0,137$ & $-0,098$ & $-0,306$ & 0,125 & $-0,252$ & $-0,203$ & $-0,313$ & $-0,205$ \\
\hline
\end{tabular}


By following the graphics describing the temperatures evolution, and the regression equations of those graphics, it can be noted that the regression equations curves have negative values, determining an angle of inclination in the range of $-0.092^{\circ}$ and $-0.392^{\circ}$ (Table 3).

\subsection{Second studied case results}

For the "9-3" position, the ANOVA analysis of the hands temperature rejects the hypothesis that subjects could have the same average temperature, at the right hand with a coefficient of $p=7.8 \cdot 10^{-205}$, while the left hand has a coefficient of $p=1.2 \cdot 10^{-248}$, the coefficients being higher than those in the "10-2" position. For each subject the correlation analysis of the same parameters (time, temperature, average) for each hand to a certain time, had values that enclose data in the weaker correlation zone.

The behaviour, somehow aleatory, of the hands' temperature in the "9-3" position is emphasised by the regression analysis which, even if it associates them in a linear way, has the angles value equal to the curve value with both positive and negative values, meaning that there are cases when the temperature was rising with $30 \%$, and times when the temperature has dropped with $70 \%$ in the case of all subjects (Tables 3 and 4).

Table 3. Regression analysis estimated values for the right hand in the "9-3" position.

\begin{tabular}{|c|c|c|c|c|c|c|c|c|c|c|c|}
\hline & $\begin{array}{c}\text { SUB } \\
1\end{array}$ & $\underset{2}{\text { SUB }}$ & $\begin{array}{c}\text { SUB } \\
3\end{array}$ & $\begin{array}{c}\text { SUB } \\
4\end{array}$ & $\begin{array}{c}\text { SUB } \\
5\end{array}$ & $\begin{array}{c}\text { SUB } \\
6\end{array}$ & $\begin{array}{c}\text { SUB } \\
7\end{array}$ & $\begin{array}{c}\text { SUB } \\
8\end{array}$ & $\begin{array}{c}\text { SUB } \\
9\end{array}$ & $\begin{array}{c}\text { SUB } \\
10\end{array}$ & AVERAGE \\
\hline Intercept & 23,732 & 31,019 & 29,519 & 24,589 & 27,278 & 29,184 & 32,427 & 27,781 & 31,966 & 33,517 & 28,971 \\
\hline Curve & $-0,001$ & 0,002 & $-0,005$ & $-0,001$ & 0,016 & $-0,003$ & $-0,001$ & 0,0045 & $-0,0035$ & $-0,0016$ & 0,0018 \\
\hline ANGLE $^{\circ}$ & $-0,057$ & 0,161 & $-0,328$ & $-0,090$ & 0,748 & $-0,185$ & $-0,084$ & 0,255 & $-0,199$ & $-0,093$ & 0,107 \\
\hline
\end{tabular}

Table 4. Regression analysis estimated values for the left hand in the "9-3" position.

\begin{tabular}{|c|c|c|c|c|c|c|c|c|c|c|c|}
\hline & $\underset{1}{\text { SUB }}$ & $\begin{array}{c}\text { SUB } \\
2\end{array}$ & $\begin{array}{c}\text { SUB } \\
\mathbf{3}\end{array}$ & $\begin{array}{c}\text { SUB } \\
4\end{array}$ & $\begin{array}{c}\text { SUB } \\
5\end{array}$ & $\begin{array}{c}\text { SUB } \\
6\end{array}$ & $\begin{array}{c}\text { SUB } \\
7\end{array}$ & $\begin{array}{c}\text { SUB } \\
8\end{array}$ & $\begin{array}{c}\text { SUB } \\
9\end{array}$ & $\begin{array}{c}\text { SUB } \\
10\end{array}$ & AVERAGE \\
\hline Intercept & 24,539 & 32,147 & 29,679 & 24,940 & 28,037 & 29,579 & 30,949 & 27,781 & 31,966 & 33,517 & 29,313 \\
\hline Curve & $-0,003$ & 0,002 & $-0,000$ & $-0,001$ & 0,014 & $-0,001$ & $1,61 \mathrm{E}-05$ & 0,004 & $-0,003$ & $-0,001$ & 0,0010 \\
\hline ANGLE $^{\circ}$ & $-0,191$ & 0,147 & $-0,034$ & $-0,064$ & 0,682 & $-0,058$ & 0,0009 & 0,255 & $-0,199$ & $-0,093$ & 0,057 \\
\hline
\end{tabular}

By analyzing the temperature and the regression graphics, it can be noticed that for $70 \%$ of the subjects the right-hand temperature was dropping, the average temperature were rising. This explains why the correlation values were smaller.

Analogous with the right hand, the drop-in temperature of the left hand in the "9-3" position is observed in most cases, $60 \%$ of the subjects, with a little variation of the regression curve, reason why the regression average graphic is almost horizontal, but with the same weak correlation between the registered temperatures and average.

\subsection{Results for the position of the hands in the "5-7" zone}

From the ANOVA analysis, it resulted, for the position of the hands on the steering wheel in the "5-7" zone, the coefficients $\mathrm{p}=5.8 \cdot 10^{-281}$ for the right hand and $\mathrm{p}=6.8 \cdot 10^{-228}$ for the left hand, emerging from here that the data are statistically meaningful.

From a Pearson correlation point of view, between the temperatures of the right hand and average was possible to observe that in $80 \%$ of the cases, the correlation is positive, and only in $20 \%$ negative. It is registered a strong correlation between the registered temperatures and average for $60 \%$ of the subjects. The left hand presents the same percentage as the subjects with positive and negative correlation, but only $70 \%$ of these subjects have a strong correlation between the temperature and average on a 300 seconds interval.

By analyzing the curve's equation's angle of temperatures regression, it was observed that, both for right hand and left hand, the inclination angle was much smaller than those for the other hand position on the steering wheel (Tables 5 and 6). 
Table 5. Regression analysis estimated values for the right hand in the "5-7" position.

\begin{tabular}{|c|c|c|c|c|c|c|c|c|c|c|c|}
\hline & $\begin{array}{c}\text { SUB } \\
1\end{array}$ & $\begin{array}{c}\text { SUB } \\
2\end{array}$ & $\begin{array}{c}\text { SUB } \\
\mathbf{3}\end{array}$ & $\begin{array}{c}\text { SUB } \\
4\end{array}$ & $\begin{array}{c}\text { SUB } \\
5\end{array}$ & $\begin{array}{c}\text { SUB } \\
6\end{array}$ & $\begin{array}{c}\text { SUB } \\
7\end{array}$ & $\begin{array}{c}\text { SUB } \\
8\end{array}$ & $\begin{array}{c}\text { SUB } \\
9\end{array}$ & $\begin{array}{c}\text { SUB } \\
10\end{array}$ & AVERAGE \\
\hline Intercept & 23,775 & 30,531 & 29,207 & 24,983 & 28,572 & 30,204 & 32,557 & 32,473 & 27,719 & 33,222 & 29,324 \\
\hline Curve & $1,21 \mathrm{E}-05$ & $-0,0012$ & 0,0076 & $-0,0021$ & $-0,0019$ & $-0,0084$ & 0,0003 & $-0,0050$ & $-0,0034$ & $-0,0019$ & $-0,0016$ \\
\hline ANGLE ${ }^{\circ}$ & 0,0006 & $-0,068$ & 0,413 & $-0,123$ & $-0,112$ & $-0,452$ & 0,0173 & $-0,281$ & $-0,194$ & $-0,112$ & $-0,093$ \\
\hline
\end{tabular}

Table 6. Regression analysis estimated values for the hand in the "5-7" position.

\begin{tabular}{|c|c|c|c|c|c|c|c|c|c|c|c|}
\hline & $\begin{array}{c}\text { SUB } \\
1\end{array}$ & $\begin{array}{c}\text { SUB } \\
2\end{array}$ & $\begin{array}{c}\text { SUB } \\
3\end{array}$ & $\begin{array}{c}\text { SUB } \\
4\end{array}$ & $\begin{array}{c}\text { SUB } \\
5\end{array}$ & $\begin{array}{c}\text { SUB } \\
6\end{array}$ & $\underset{7}{\text { SUB }}$ & $\begin{array}{c}\text { SUB } \\
8\end{array}$ & $\begin{array}{c}\text { SUB } \\
9\end{array}$ & $\begin{array}{c}\text { SUB } \\
10\end{array}$ & AVERAGE \\
\hline Intercept & 24,528 & 31,539 & 31,448 & 25,255 & 28,965 & 31,683 & 29,834 & 31,840 & 28,593 & 32,814 & 29,650 \\
\hline Curve & $-0,0017$ & $-0,0003$ & $-0,0074$ & $-0,0014$ & 0,0009 & $-0,0111$ & 0,0063 & $-0,0037$ & $-0,0035$ & $-0,0036$ & $-0,0025$ \\
\hline ANGLE $^{\circ}$ & $-0,096$ & $-0,022$ & $-0,405$ & $-0,082$ & 0,0549 & $-0,567$ & 0,347 & $-0,213$ & $-0,199$ & $-0,204$ & $-0,146$ \\
\hline
\end{tabular}

The temperature and regression graphics confirms the good correlation in what the average is concerning and present a smaller variation of the regression curve comparatively with the "10-2" position. At most subjects, both the right-hand temperature and left-hand temperature is dropping, being in line with the average temperature graphic.

\section{Discussion}

To maintain a constant temperature in the human body depends on the equilibrium between the production of warmth (thermogenesis) and the loss of warmth (thermolysis). This balance could be influenced by the environment's temperature, which constitutes an important factor for the subjects' performance, as well as for the body position and the intensity of the action. The phenomenon of thermolysis shall be realized through skin/leather, heat exchange between the one previously mentioned and the bodies due to coming in direct contact (conduction), irradiation or convection within an external environment. The blood has been entitled "the heat transfer fluid of the human body", realizing the heat transport from inside (internal organs) outward (skin) through its vessels and arteries. If the normal temperature of the human body has recorded values of $36.1^{\circ} \mathrm{C}$ in the morning and $37.2^{\circ} \mathrm{C}$ after sunset, the temperature of the skin scarcely exceeds $34.0^{\circ} \mathrm{C}$. When the human body is exposed to chilled temperatures, the heat transfer is much more likely to be reduced due to the alleviation of the contact surface between the blood vessels and the skin (vasoconstriction). The vasoconstriction can also be influenced from the outside through both constriction and obstruction of the blood vessels in either conscious or in conscious state of mind (physiological paraesthesia). Moreover, the narrowing of the blood vessels may also happen if the heart is not capable of pumping enough blood, vital for the irrigation of the human body parts who require an augmentation of blood pressure. This phenomenon occurs in the human activities which require the use of hand (painting, playing basketball, repairing and renovating buildings, etc).

For example, by considering the subjects analyzed in the present study it is possible to state the fact that vasoconstriction takes place when the analyzed subjects put their hands on the steering wheel in both the "10-2" and "5-7" zone. As a result, their hands' temperature decreases. This reduction has been felt by the subjects after about 4 minutes $75 \%$ of them declared that they felt discomfort from the fingers' zone (skin itching, lulls).

The diminution of the temperature in the "10-2" position can be caused by the difference of potential between the contact zone of the hands and the heart. This difference would oblige the heart to raise the blood pressure, also causing a raise of the internal temperature of the body and the overtaking of the normal skill. This thing is not beneficial for the internal organs. That's why the organism keeps constant its internal temperature and it gives up to the attempt of trying to defeat the difference of potential, resulting in the diminution at the finger level.

The behaviour of the temperatures in the "5-7" position is due to the choking of the blood vessels in the case of few subjects, because it represents an uncomfortable position 
both for the hand, as well as for its kinematic. This position is not commonly found in responsible drivers being the proprioceptive sensors which provide data about the form and the position.

In what concerns the hands' position on the steering wheel in the "9-3" zone the thermal analysis of the hands has proved that this (position) is optimal. The average temperature of the subjects, at every 10 seconds, showed that for the right hand the temperature is rising with approximately $0.5^{\circ} \mathrm{C}$, and for the left hand the temperature remains approximately constant.

\section{Conclusions}

By following the thermic analysis of the hands' temperature in various positions on the steering wheel in static regime, the following conclusions can be drawn:

- the positioning of the hands in the "10-2" zone is the most disadvantageous from the blood circulation point of view, reason why in the case of all subjects the temperature is dropping, with a linear tendency, having a strong correlation in what concerns the average.

- by putting the hands in the "5-7" position it was proven to be the most advantageous solution from the thermic point of view, than the positioning in the "10-2" zone, the curve of the regression' equations being smaller, but it represents an uncomfortable position from a driver's.

- the thermic analysis of the hands in the "9-3" position has proved to be the best solution, the variations of the temperature being insignificant for 5 minutes, by considering that those variations were due to the warmth change with the exterior and because of the thermoregulatory change caused by from the fingers.

\section{References}

1. D. Ganea, E. Mereuta, C. Mereuta, Applied Mechanics and Materials, 555, (2014)

2. S. Saha, M. Pal, A. Konar, D. Bhattacharya, In Information Systems Design and Intelligent Applications, (2015)

3. D. Ganea, M. S. Tudoran, C. Mereuta, E. Mereuta, Annals of "Dunărea de Jos" University of Galati, XV, (2012)

4. E. Mereuta, D. Ganea, C. Mereuta, Applied Mechanics and Materials, 555, (2014)

5. D. Ganea, et al., MATEC Web of Conferences, 112, (2017)

6. D. Walton, J.A. Thomas, Transportation Research Part F: Traffic Psychology and Behaviour, 8, (2005)

7. M. Fourie, D. Walton, J.A. Thomas, Transportation Research Part F: Traffic Psychology and Behaviour, 14, Issue 5, (2011)

8. J. Hartley, Transportation Research Part F: Traffic Psychology and Behaviour, 42, (2016) 